\title{
Legal fees nearly double for many MDs
}

$\mathrm{N}$ egotiations will begin in September to ease the pain of medico-legal fee hikes of $95 \%$ in 2015 for Canadian physicians outside Ontario and Quebec. The nonprofit Canadian Medical Protective Association (CMPA), which provides legal assistance to physicians and pays financial awards to successful plaintiffs, says one option may be to amortize $50 \%$ of the increase over more years.

The CMPA's cost estimate is generated by actuarial models that follow industry best practices. The CMPA's Executive Director and CEO Dr. Hartley Stern says approximately half the fee increase outside Ontario and Quebec is because of higher than estimated costs, chiefly compensation to injured patients. The other half of that increase represents CMPA's attempt to catch up financially and return to a fully funded position over the next five years.

Those hardest hit are outside Ontario and Quebec - a region the CMPA calls the "rest of Canada" - where the 2015 annual fees will rise $95 \%$, to an average of $\$ 5948$ from $\$ 3046$. In Ontario, fees will increase 18\% in 2015, to an average of $\$ 7628$ from $\$ 6445$. In Quebec, the average fee will remain unchanged at $\$ 4130$. Fees in each of the three regions are calculated based on that area's settlements and expenses.

Stern says that while fees for 2015 have already been set, consideration will be given to extending the amortization period for future years. "However, a change to a six- or seven-year amortization would make a fairly marginal difference to members," says Stern. "The number will be roughly the same if the cost trends don't change." The possibility of extending the amortization period will be resolved before 2016 fees are set.

"We're working very hard to bring those fees down," adds Stern, who is travelling across Canada this fall to talk with medical associations and health ministries.

The 2015 fee increase will be partly borne by taxpayers. Every provincial

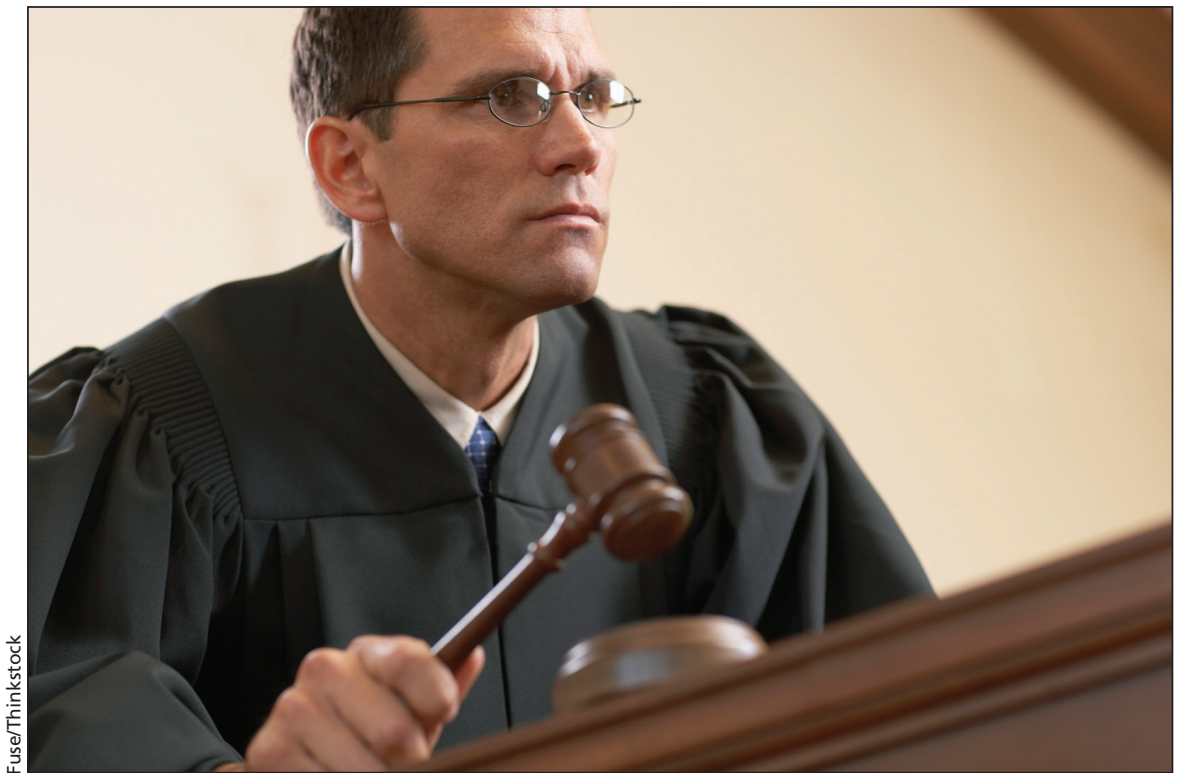

The number of medical civil suits is declining, but the cost of settlements is "skyrocketing," says the Canadian Medical Protective Association.

and territorial government has an agreement with its medical association to pay a portion of CMPA fees in lieu of other forms of compensation. Saskatchewan, which arguably has the greatest need to attract and retain physicians, pays $100 \%$ of protection fees.

In Alberta, each physician pays $\$ 1000$ annually to CMPA, regardless of specialty, with the government picking up the remainder, said Shannon Rupnarain, spokesperson for the Alberta Medical Association in a statement. "The actual 2015 fees have not been released yet, so we really do not have any more detail," she added.

Fees vary according to a physician's specialty. In British Columbia, for example, the 2014 average was $\$ 6000$, but that ranged from a low of $\$ 1900$ for family physicians to a high of $\$ 20300$ for obstetricians.

Physician associations in $\mathrm{BC}$ and Nova Scotia are among those negotiating fee agreements with provincial governments; the CMPA increase will be part of those discussions.

In $\mathrm{BC}$, the government now pays about half the fees. "We won't know the impact of a CMPA fee increase on doctors until we complete our negotiations," said Doctors of BC President Dr. Bill Cavers in a succinct statement.

The government of Nova Scotia pays $90 \%$ of CMPA dues that exceed $\$ 1500$ annually, but that agreement expires Mar. 31, 2015. "Right now, there is a huge subsidy," says Kevin Chapman, director of health policy and promotion for Doctors Nova Scotia. "We're looking at what opportunity we have [to reduce fees for physicians]."

Chapman calls the increase "staggering," pointing out that unlike businesses, which can hike prices when expenses rise, doctors are committed to a fee schedule. "Members are upset," although there is "some hope" part of the increase could be amortized beyond five years.

In addition to discussions on extending the amortization, CMPA is launching initiatives to control increases. These include bumping up educational offerings to physicians; in 2013 , its 450 programs attracted 24000 health professionals.

The association will also talk with provincial and territorial ministries of justice with the aim of containing the cost of damage payments. "What is the 
economic basis of awarding in one province, three times what is awarded for the same injury in another province?" asks Stern. "There are also many system inefficiencies that drive up costs but do not benefit the injured patient. I don't want the message out there that we're shirking our responsibility. We just want logic and equity in awarding damages across Canada."

The association is also looking for ways to reduce the length of time that cases take in an effort to mitigate legal costs, which is the second biggest expense after awards and settlements. Stern says they're continuing to work with their law firms to accelerate the pace of court action but this needs support from the justice system.

The CMPA determines its fees by forecasting the costs of providing protection in the upcoming year. In 2008, CMPA estimated the cost of protection for 2009 would be $\$ 321$ million; for 2015 , the projection is $\$ 503$ million an increase of $64 \%$.

The number of civil lawsuits actually declined by $40 \%$ between 2004 and 2013, according to the CMPA 2013 Annual Report. In 2013, there were 842 new legal cases, the lowest number in many years and well below the peak of 1415 cases in 1995. Stern says this decrease is partly due to the expense of litigation, which is causing lawyers to be more selective about the cases they take.

While suits are down, recent payment history and cost trends have "skyrocketed," according to Stern. In the past two to three years, CMPA has seen a marked increase in protection costs in Ontario and, more recently, the "rest of Canada." CMPA saw these, initially, as "blips." Settlements for cases involving compromised infants now reach $\$ 12$ to $\$ 14$ million in Ontario, so an additional five cases in one year can substantially influence the trends, says Stern.

"At three years, it's not a blip; it's something to act upon," says Stern. Given the CMPA's commitment to ensure the costs of supporting today's physicians are not deferred to the next generation of doctors, "your fiduciary requirement is to act ... it's not like you have an option."

In 2013, median damages to patients reached $\$ 161000 ; 18 \%$ higher than in 2011. Legal expenses increased $14 \%$ over 2012 , to $\$ 43000$ per case. CMPA warned the provincial and territorial medical associations in 2013 that "we were worried about cost damages going up in the rest of Canada," says Stern. It reiterated these concerns at its annual meeting. "We didn't expect it to be this high, this volatile." - Barbara Sibbald, CMAJ

CMAJ 2014. DOI:10.1503/cmaj.109-4898

\section{MediData: How potent is medical marijuana?}

$\mathrm{T}$ he main psychoactive component of marijuana, delta-9tetrahydrocannabinol (THC), varies in concentration from strain to strain but, in general, much of the medical cannabis that Canadian licensed growers plan to sell appears to be quite potent. In a June 2014 commentary in CMAJ, two physicians suggested that, based on available clinical evidence, prescriptions should specify that THC concentrations not exceed $9 \%$.

As can be seen on this graph, displaying the potency of the products listed on the websites of five growers, very few strains contain THC concentrations of $9 \%$ or lower, assuming these figures are accurate.

Also of note: most of the strains on the websites of growers that offer only a few products (like CanniMed and Bedrocan) have distinct THC concentrations. Those with more extensive catalogues list many strains with similar THC levels. Cannimed (5 products) told $C M A J$ that many of the strains sold by companies with wide selections are so similar - high in THC, low in cannabidiol (CBD) - that they offer no

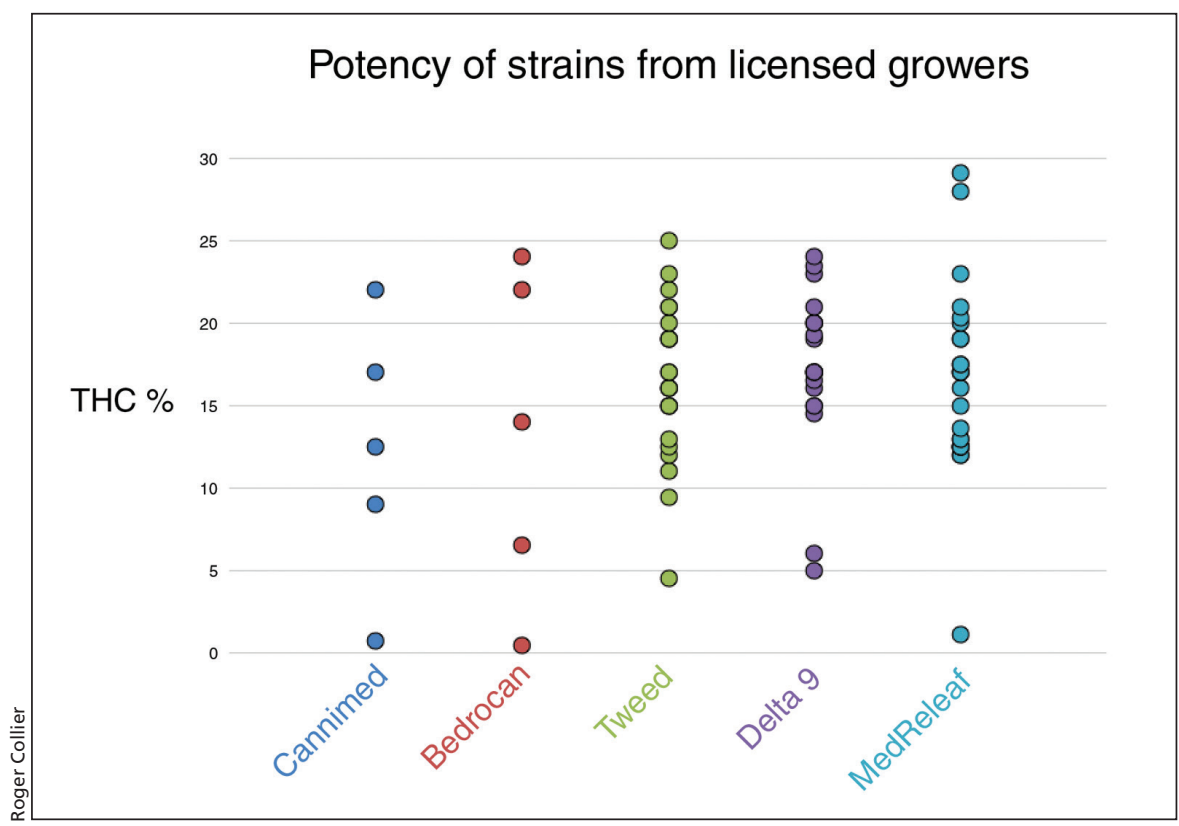

unique therapeutic benefits. But Tweed (23 products) suggested to $C M A J$ that there is much more to cannabis than just THC and CBD. There are more than 400 components in cannabis, the grower noted, and it's possible that varying those components could offer therapeutic benefits, even if THC levels are similar.
Of course, there is little clinical evidence yet to support either claim, which may explain why conversations about the specific medical benefits of marijuana tend to be peppered with a particular word: "anecdotally." Roger Collier, CMAJ 